\title{
Corrigendum: Melatonin Application in Assisted Reproductive Technology: A Systematic Review and Meta-Analysis of Randomized Trials
}

\section{OPEN ACCESS}

Approved by:

Frontiers Editorial Office,

Frontiers Media SA, Switzerland

*Correspondence:

Dan Zhang

zhangdan@zju.edu.cn

TORCID:

Dan Zhang

orcid.org/0000-0003-1295-4795

Specialty section:

This article was submitted to

Reproduction

a section of the journal

Frontiers in Endocrinology

Received: 27 April 2020

Accepted: 28 April 2020

Published: 19 May 2020

Citation:

Hu K-L, Ye X, Wang S and Zhang $D$

(2020) Corrigendum: Melatonin Application in Assisted Reproductive Technology: A Systematic Review and Meta-Analysis of Randomized Trials.

Front. Endocrinol. 11:333.

doi: 10.3389/fendo.2020.00333

\author{
Kai-Lun $\mathrm{Hu}^{1,2}$, Xiaohang $\mathrm{Ye}^{1,2}$, Siwen Wang ${ }^{1,2}$ and Dan Zhang ${ }^{1,2 * t}$ \\ ${ }^{1}$ Key Laboratory of Reproductive Genetics, Ministry of Education, Department of Reproductive Endocrinology, Women's \\ Hospital, Zhejiang University School of Medicine, Hangzhou, China, ${ }^{2}$ Key Laboratory of Women's Reproductive Health of \\ Zhejiang Province, Hangzhou, China
}

Keywords: melatonin, assisted reproductive technology, randomized trial, in vitro fertilization, systematic review and meta-analysis

\section{A Corrigendum on}

Melatonin Application in Assisted Reproductive Technology: A Systematic Review and Meta-Analysis of Randomized Trials

by Hu, K.-L., Ye, X., Wang, S., and Zhang, D. (2020). Front. Endocrinol. 11:160. doi: $10.3389 /$ fendo.2020.00160

In the original article, we neglected to include the "National Natural Science Foundation of China" and the "Fundamental Research Funds for the Central Universities" as funders. In addition, we didn't include the grant number "2017YFC1001003" for the National Key Research and Development Program. The corrected Funding statement appears below.

\section{FUNDING}

"This study was supported by the National Key Research and Development Program of China (2018YFC1005003, 2017YFC1001003), the National Natural Science Foundation of China (No. 81974224, 81771535), the Fundamental Research Funds for the Central Universities, the Natural Science Foundation of Zhejiang Province (No. LZ18H040001), Zhejiang University Scholarship for Outstanding Doctoral Candidates, and Zhejiang University Education Foundation Global Partnership Fund."

In addition, there were errors in the affiliations of the authors. Affiliation 1 should be "Key Laboratory of Reproductive Genetics, Ministry of Education, Department of Reproductive Endocrinology, Women's Hospital, Zhejiang University School of Medicine, Hangzhou, China.” The following has been added as affiliation 2:

Key Laboratory of Women's Reproductive Health of Zhejiang Province, Hangzhou, China.

The authors apologize for this error and state that this does not change the scientific conclusions of the article in any way. The original article has been updated.

Copyright $\odot 2020 \mathrm{Hu}, Y e$, Wang and Zhang. This is an open-access article distributed under the terms of the Creative Commons Attribution License (CC BY). The use, distribution or reproduction in other forums is permitted, provided the original author(s) and the copyright owner(s) are credited and that the original publication in this journal is cited, in accordance with accepted academic practice. No use, distribution or reproduction is permitted which does not comply with these terms. 